\title{
Erratum to: Variability of State School-Based Hearing Screening Protocols in The United States
}

\author{
Deepa L. Sekhar ${ }^{1}$ Thomas R. Zalewski ${ }^{2}$ Ian M. Paul ${ }^{1,3}$
}

Published online: 26 May 2016

(C) Springer Science+Business Media New York 2016

\section{Erratum to: J Community Health (2013) 38:569-574 \\ DOI 10.1007/s10900-013-9652-6}

Unfortunately, the original version of this article contained a mistake in one sentence of "Results" section. That is, the sentence should have included "Maine" not "Maryland".
The correct sentence should read as:

Specifically, protocols from Tennessee, Missouri, Mississippi and Maine recommend the inclusion of 6 and/or $8 \mathrm{kHz}$, but these frequencies are not required frequencies to be screened.

The online version of the original article can be found under doi:10.1007/s10900-013-9652-6.

Deepa L. Sekhar

dsekhar@hmc.psu.edu

1 Department of Pediatrics, Penn State College of Medicine, 500 University Drive, HS83, Hershey, PA 17033, USA

2 Department of Audiology, Bloomsburg University, $400 \mathrm{E}$ 2nd Street, Bloomsburg, PA 17815, USA

3 Department of Public Health Sciences, Penn State College of Medicine, 500 University Drive, HS83, Hershey, PA 17033, USA 